\title{
Türkiye’deki Kamu ve Özel Hastane Web Sitelerinin İşleyiş Kalitesi, Güncellik ve Tasarım Altyapısı Bakımından Analizi*
}

\author{
Sümeyra BOYDAK, Necmettin Erbakan Üniversitesi, Sağlık Bilimleri Enstitüsü, \\ suboydak@gmail.com, (D) 0000-0003-2445-8879
}

Yusuf Yalçın İLERİ, Necmettin Erbakan Üniversitesi, Sağlık Yönetimi Bölümü, Doç. Dr., yileri@erbakan.edu.tr, (DD 0000-0002-3911-1192

$\ddot{O Z Z}$

\begin{abstract}
Günümüzde internete erişimin kolaylaşması ve internete erişim araçlarmın ucuzlayarak yaygınlaşması işletmeleri kurumsal kimliklerini sunabilecekleri iyi tasarlanmış, yaşayan ve sürekli gelişen web siteleri kurmaya yöneltmiştir. Web siteleri kurumların görünen yüzü haline gelmiştir. Ziyaret eden kullanıclarmn kurum hakkında ve kurumun sunduğu ürün ve hizmetler hakkında ilk izlenimleri web sitelerinin sunabildiğgi kalite ile doğrudan ilişkilidir. Internet yayginlaştıkça artan bilgi kirliliği ise özellikle sağlık sektöründe hizmet talep edenler açısından büyük bir problem haline gelmiştir. Bu noktada, sağllk kurumları açısından hastalarn doğru, güvenilir ve güncel bilgileri alabilecekleri en önemli araç hastane web siteleridir. Hastane web sitelerinin kullanıc dostu, kolay erişilebilir ve anlaşılabilir şekilde tasarlanması, interaktif bir yapıda olması ve hastaların ihtiyaç duyacakları bilgileri güncel şekilde sunabilmesi kritik önemdedir.

Bu çalışmanın amacı, Türkiye'deki üniversite, devlet ve özel hastanelerin kurumsal web sitelerinin; kullanılabilirlik, erişim kalitesi, performans, güncellik, teknik altyapr ve sosyal boyut açısından belirlenen kriterler vasıtasıyla incelemektir. Çalışmanın örneklemi, Türkiye'nin Marmara, İç Anadolu, Ege, Akdeniz, Güneydoğu Anadolu, Karadeniz ve Doğu Anadolu Bölgelerinden seçilerek kapsama alınan toplam 252 hastane web sitesidir. Hastane web siteleri, arama motoru optimizasyonu algoritmaların kullanan bir yazılım aracllğ̆ıla, 6 ana boyut altında yer alan 22 kriter üzerinden analiz edilmiştir. Araştırma sonuçları özellikle özel hastane web sitelerinin daha tatmin edici sonuçlar vermelerine rağmen, Türkiye'deki hastane web sitelerinin genel olarak güncellik, sosyal boyut, görsellik ve içerik kalitesi noktasında önemli geliştirmelere ihtiyaç duyduğunu göstermektedir.
\end{abstract}

Anahtar : $\quad$ Web Sitesi, Hastane, İnternet Teknolojileri, Sağllk Yönetimi

*Bu çalışma, Necmettin Erbakan Üniversitesi Sağlık Bilimleri Enstitüsü Sağlık Yönetimi A.D.'nda Doç. Dr. Yusuf Yalçın İLERİ danışmanlığında, Sümeyra BOYDAK tarafından 2019 yılında hazırlanan aynı isimli yüksek lisans tezinden üretilmiştir. 


\title{
Analysis of Public and Private Hospital Web Sites in Turkey in Terms of Functioning Quality, Updating and Design Infrastructure
}

\begin{abstract}
Today, the ease of access to the internet and the cheaper and widespread use of internet access tools have led businesses to establish well-designed, living and constantly developing websites where they can present their corporate identity. Web sites have become the visible face of institutions. The first impressions of the visiting users about the institution and about the products and services offered by the institution are directly related to the quality of the websites. Information pollution, which increases as the Internet becomes widespread, has become a major problem especially for those who demand service in the health sector. At this point, the most important tool by which patients can get accurate, reliable and up-to-date information for health institutions is hospital websites. It is critical that hospital websites are designed in a user-friendly, easily accessible and understandable manner, have an interactive structure, and provide up-to-date information that patients need.

The aim of this study is to examine the usability, access quality, performance, upto-dateness, technical infrastructure and social dimension of government and private hospital websites in Turkey. The sample of the study includes 252 hospital websites of Turkey's Marmara, Central Anatolia, Aegean, Mediterranean, Southeast Anatolia, the Black Sea and Eastern Anatolia regions. Hospital websites were analyzed over 22 criteria under 6 main dimensions, using a software that uses search engine optimization algorithms. Despite getting more satisfactory research results for especially private hospital websites, results present that hospital websites in Turkey need significant improvement on the timeliness, social dimension, visuality and content quality.
\end{abstract}

Keywords : $\quad$ Website, Hospital, Internet Technologies, Health Management

\section{GİRIŞ}

Günlük yaşamın her alanında etkin bir rol oynayan bilgi iletişim teknolojilerinin gelişmesi, işletmelerin çağımızın vazgeçilmezlerinden biri olan internet ortamında var olmalarını zorunlu hale getirmiştir. İnternetin müşterilere ulaşmada etkin şekilde kullanımı, kurumlara rekabet üstünlüğü sağlar, doğru ve zamanında bilgi paylaşımına imkân verir, müşteri sadakatini artırır ve bunu alternatif yöntemlere göre nispeten ucuz ve güvenilir bir şekilde sunar (İleri, 2018, s. 33,12). Covid-19 pandemi dönemi açıcça göstermiştir ki; başta hastaneler olmak üzere sağlık hizmeti sunan kurumların varlıklarını başarılı bir şekilde sürdürebilmeleri, hedef kitlelerinin (hastalar/hasta yakınları, çalışanlar, tedarikçiler vb.) zihinlerinde oluşturdukları pozitif algıyla çok ilintilidir. Bu noktada, olumlu kurum imajı ve güçlü kurum itibarının oluşması sürecine internet son derece önemli katkılar sağlayacaktır.

Hastaneler, paydaşlarına elektronik olarak hizmet sunmak amacıyla, genel olarak bilgi ve iletişim teknolojilerinden yararlanmakta, halka özellikle de web siteleri üzerinden 
kolaylaştırıcı ve destekleyici bilgiler sunarak benzersiz faydalar sağlamaktadırlar (Patsioura vd., 2009, s. 226). Hastanelerin web sitesi kalitesinin, hastaların ilgili kurumu önerme istekliliği ile güçlü ve pozitif yönde ilişkisi bulunmaktadır Hastane web sitesinin kaliteli, kullanışlı, hızlı ve sorunsuz olması, kullanıcıların faydalanması ve tercihi açısından büyük önem taşımaktadır. (Ford vd., 2013, s. 346).

Dünyadaki internet ve sosyal medya kullanımına ilişkin raporlara göre 2019 yılında dünyada yaklaşık 4,5 milyar insan internet kullandığı ve bunun dünya nüfusunun yaklaşık \%60'ını oluşturduğu ve bu oranın hızla arttı̆̆ı görülmektedir (wearesocial.com). Bu oranlar her alanda olduğu gibi sağlık alanında da insanlara internet üzerinden ulaşmanın çok etkili bir yol olduğunu gösterir.

Hastane web sitelerinin kullanıcılara bilgi sağlanmada iki temel amacı vardır. Bunlardan ilki, kişiye en uygun tıbbi hizmetin seçimine yönelik karar vermesine destek olmak, ikincisi ise, sağlığı iyileştirmek ve tüketicilere kendi sağlıklarının yönetiminde yardımcı olmak için genel veya özel sağlık bilgilerinin güvenilir bir kaynağı olarak hizmet etmektir (Patsioura vd., 2009, s. 225).

Bir hastanenin ana sayfası birçok durumda önemli ilk temas noktasıdır. Sonuç olarak web sitesi, organizasyonun mevcut ve potansiyel müşterilerine olduğu kadar hastaya eşlik eden ziyaretçiler için de önemli bir araç haline gelmiştir. Bir hastanenin web sitesi, hastaların önceki tecrübelerine dayanarak oluşturdukları beklentilerine uymuyorsa veya bunları aşamıyorsa, bu müşterilerin karar verme süreçlerini olumsuz yönde etkileyebilecektir (Ford vd., 2012 s. 48).

Huang (2015, s. 27)'a göre hastaneler, bilişim teknolojileri gelişiminde güçlü bir uzmanlığa sahip oldukları sürece, hastalarına hizmet etmek için verimli bir web sitesi oluşturma konusunda başarılı olabileceklerdir. Hastalara iyi hizmet verebilmek için oldukça yetkin bir hastane web sitesi geliştirmenin, uzmanlık, dayanışma ve farkındalık gerektirdiği konusunda görüş birliği bulunmaktadır. Bu noktada, sağlık kurumları açısından hastaların doğru, güvenilir ve güncel bilgileri alabilecekleri en önemli aracın hastane web siteleri olması nedeniyle, hastane web sitelerinin kullanıcı dostu, kolay erişilebilir ve anlaşılabilir şekilde tasarlanması, interaktif bir yapıda olması ve hastaların ihtiyaç duyacakları bilgileri güncel şekilde sunabilmesi kritik önemdedir denilebilir.

Bu araştırmanın amacl; Türkiye'deki üniversite, devlet ve özel hastanelerin kurumsal web sitelerini; (1) kullanılabilirlik, (2) erişim kalitesi, (3) performans, (4) güncellik, (5) teknik altyapı ve (6) sosyal boyut ana başlıkları üzerinden analiz etmek ve hastanelerin web siteleri aracılığıyla kullanıcılara sundukları hizmetlerin kalitesine ilişkin bulgular elde etmektir. 


\section{1. İnternet ve Sosyal Medyanın Sağlık Sektöründeki Yeri}

İnternet günümüzde sağlık sektöründe, çevrimiçi sağlık bilgisi ve sağlık hizmetleri arayan tüketiciler için önemli bir kitle iletişim ortamı haline gelmiştir (Liu vd., 2011, s. 1554). İnternet teknolojilerinin gelişimi ile sağlık hizmetleri konusunda birçok yapısal dönüşüm de beraberinde gelmiştir. (Ardıç Çobaner ve Köksoy, 2014, s. 901). İnternet ve özellikle hastane web siteleri dünyada sağlık konusundaki başvuru kaynaklarında ilk sırada yer almaktadır (İleri, 2018, s. 12).

Günümüzde internetin sağlık hizmetleri için kullanımı, bireylerin sağlık web siteleri üzerinden ulaşılabildiği tüm hizmet ve aktiviteleri kapsamaktadır. Geniş bir kapsamı olan bu hizmet ve faaliyetlere; sağlık enformasyonu içeren web siteleri üzerinden kurumların hizmet sunduğu uzmanlık alanları, doktorlar ve eğitimleri, sunulan sağlık hizmetleri ve ürünleri ile ilgili detaylı bilgiler verilmesi, temel sağlık planlarına erişim fırsatları, özel sağlık bilgilerinin araştırılması, bültenler ve uzman doktorun katılımıyla gerçekleştirilen sohbet hizmetleri örnek olarak verilebilmektedir (Durdu ve Altuntaş, 2020; Şeker, 2005; Y1lmaz, 2013).

Sağlık hizmeti bilgi yoğun bir faaliyettir. Hastalar kendi sağlık kararları için daha fazla sorumluluk üstlenirken, sağlık kurumlarının web siteleri de hastalar ve hizmet sağlayıcılar arasında bilgi alışverişini kolaylaştırmak için uygun ve güvenilir bir ortam oluşturmaktadır. Hastaneler, hasta bakımı kalitesini ve hastalarla iletişimi arttırma ve maliyetleri düşürme konusundaki hedeflerine ulaşmak için kurumsal web sitelerini ve buradan sundukları elektronik bağlantıları giderek daha da önemsemektedirler. Kullandıkları gelişmiş bilişim teknolojileri sayesinde sağlık kurumları hastaları ile iletişim kanallarını sürekli açık tutabilmekte, karşılıklı beklentilerini daha iyi yönetebilmektedirler (Gruca ve Wakefield, 2004, s. 1022; İleri, 2018, s. 12).

Sağlık kurumlarının web sitelerinin kullanılabilirliğinin, kullanıcıların psikolojik algıları üzerinde önemli etkilere sahip olduğu bilinmektedir. Kullanıcıların hızlı bir şekilde ilgili bağlantıları bulmalarına yardımcı olmak için sayfa tasarımının karmaşıklıktan uzak ve anlaşılır olması gerekmektedir (Chen, 2018, s. 84). Yapılan çalışmalar, sağlık kurumlarının web sitelerinin özellikle ana sayfalarının iyi tasarlanmış olmasının ve kullanım kolaylı̆̆ sağlamasının hastalar üzerinde olumlu bir izlenim bıraktığını belirtmektedir. Ana sayfalar; uzun yazılardan uzak ve önemli bağlantıları içerecek şekilde hazırlanmalı, tüm alt sayfalarda da ana sayfaya erişebilmek için bağlantı bulunmalıdır (Dunne vd., 2013, Durmuş ve Çağıltay, 2012).

Mendi ve Akyazı (2016, s. 463,473) tarafından, 400 katılımcı ile gerçekleştirilen araştırma sonuçlarına göre; katılımcılardan 194 kişi sağlıkla ilgili bir konu hakkında bilgi almak için 166 kişi ise online hizmetleri kullanmak üzere hastane web sitelerini düzenli 
şekilde ziyaret ettiğini belirtmiştir. Bu araştırmada, eğitim düzeyi daha az olan kişilerin yüksek olan kişilere göre hastane web sitelerini daha zor kullandıkları belirlenmiştir.

372 kişi üzerinde yapılan bir çalışmada, katılımcıların \%51,9'unun hastaneye gitmeden önce web siteleri üzerinde iyi bir araştırma yaptığını, kurumun teknolojiyi takip etmesinin, hastane tercihleri üzerinde büyük oranda $(\% 84,6)$ etkisinin olduğunu göstermektedir (Yağar ve Soysal, 2017, s. 465,470).

Bir sağlık kurumunda yöneticilerle birlikte, diğer sağlık çalışanları da kurum web sayfasındaki bilgilerin doğru, güncel, yeterli ve hastalar tarafından kolay erişilebilir ve anlaşılır olduğundan emin olmalıdır. Bu sürece tüm taraflar destek olmalı, hastalardan gelen geri bildirimlere göre gerekli ekleme ve yenilikler sürekli yapılmalı, dinamik bir web sayfası oluşturulmalıdır. Yöneticilerin bu noktada farkındalığının arttırılması, sorumluluğun anlaşılması ve sürece destek verenlerin güçlendirilmesi son derece gereklidir (Liu vd., 2011, s. 1561). Bu bağlamda web siteleri, kişilerin sağlık hizmetinin her aşamasında kalite anlayışı doğrultusunda güvenle hizmet alabileceği inancının yaratılmasında, hastanenin tanıtımı açısından oldukça önemlidir (Özsarı vd., 2016, s. 211).

Yapılan araştırmalar, insanların sağlık konularıyla ilgili endişelerini gidermek ve öğrenmek istedikleri tıbbi bilgileri almak için hastane web sitelerini ziyaret ettiklerini belirtmektedir. Bir hastane web sitesinden sağlık ve tıbbi bilgi sahibi olmak, kullanıcının kuruma yönelik güven, yarar ve kullanım kolaylığı hakkındaki görüşünü olumlu yönde güçlendirir (Gallant vd., 2007, s. 18,19). Sosyal medyanın günlük yaşamın bir parçası haline gelmesi, bu mecrada sosyal medya araçları aracılığı ile hastanelerin paydaşları ile olan iletişimlerinin interaktif olarak gerçekleşmesi oldukça önemlidir. Hastaneler, web sitelerinde yer verdikleri; Facebook, Twitter, Youtube ve Instagram gibi sosyal medya araçlarıyla etkili bir sağlık iletişimi gerçekleştirme olanağına sahip olmaktadırlar.

\section{LITERATÜR ARAŞTIRMASI}

Kind vd. (2004, s. 4,5) tarafından, Amerika Birleşik Devletleri'nin önde gelen 26 çocuk hastanesinin web sitelerinin analiz edilmesi sonucunda, web sitelerinin sadece üçte birinde çocuklar ve gençler için içerik bulunduğu ve yalnızca \%10'unun son güncelleme tarihini listelediği görülmüştür.

Türkiye'de 60 Devlet Hastanesi üzerine yapılan bir araştırmada; hastane web sitelerinin \%98'inde olmayan sayfa kontrolünün bulunmadığı, \%50'sinin ise hatalı iç bağlantı içerdiği tespit edilmiştir. Bu hastanelerin kamu hastanesi olduğu halde \%51'inde reklam içeriklerinin bulunduğu görülmüştür (Başak vd., 2006, s. 79).

32 hastane web sitesinin (12 İspanyol, 10 Amerikan ve 10 İngiliz) analiz edildiği çalışmada, sadece 10 hastanenin erişilebilirlik kriterlerini karşıladığı, neredeyse hiçbirinin 
sayfanın oluşturulma tarihini veya güncelleme verilerini içermediği belirlenmiştir (Llinás vd., 2008, s. 127,128)

Uğurluoğlu (2009, s. 101) tarafından, 110 özel ve 52 kamu hastanesi web sitelerinin karşılaştırıldığı çalışmada, kamu hastane web sitelerinin, sundukları ürün ve hizmetlere ilişkin yeterince bilgi sunmadığı saptanmıştır. Hem kamu hem de özel hastane web sitelerinin güncellik ve bilgilendirme konusunda yetersiz olduğu sonucuna varılmıştır.

Maifredi vd. (2010, s. 8), İtalya'daki 419 kamu, 344 özel hastanenin web sitelerini incelemiş ve neredeyse \% 40'ının resmi bir web sitesine sahip olmadığını belgelemiştir. Teknik ögeler, hastane bilgileri ve imkânları, tıbbi hizmetler, interaktif çevrimiçi hizmetler ve dış faaliyetler boyutları adı altında incelenen sitelerde, internetin hastaneler tarafından bir iletişim aracı olarak kullanıldığı, ancak kullanıcılar ve kurum arasındaki gerçek etkileşimin sağlanamadığı tespit edilmiştir.

Hastane web siteleri kullanıcıları üzerine yapılan bir araştırmada, kişilerin hastaneyle sosyal medya üzerinden sosyalleşme konusunda yeterince heves göstermedikleri halde, hastane web sitelerinde tıbbi bilgilere, tıbbi kayıtlarına ve laboratuvar sonuçlarına ulaşma konusunda yüksek bir ilgi gösterdikleri sonucuna varılmıştır (Huang vd., 2012, s. 225).

Diğer bir çalışma, kişilerin eğitim seviyesi yükseldikçe, hastane ile ilgili sosyal medya hesaplarında yapılan yorum ve görüşler ile hastanenin web sitesindeki bilgi ve tanıtımların hasta tercihi üzerine etkisinin arttığını belirlemiştir (Metin, 2012, s. 5).

636 sağlık kuruluşu üzerinde yapılan bir çalışmada; içerik, pazarlama, kullanılabilirlik ve teknoloji boyutları incelenerek hastanelerin ve sağlı sistemleri web sitelerinin değerlendirilmesi amaçlanmıştır. En iyi ortalamaya sahip boyut, 10 üzerinden 6,42 ile içerik kalitesi olmuş, örneğin kullanılabilirlik boyutu ise 5,79 puan alabilmiştir (Ford vd., 2012, s. 54).

Alba-Ruiz vd. (2013, s. 960), incelemiş olduklarl; \%69’u kar amacı gütmeyen kuruluşlara, \%14'ü üniversitelere ve \%10'u özel tıp merkezlerine ait olan 29 hastane web sitesinin \%21'inin en temel erişilebilirlik kriterlerini karşılamadığı sonucuna varmışlardır. Çalışma sonuçları, özellikle yaşlı insanların incelenen hastane web sitelerini etkili bir şekilde göremeyeceğini, anlayamayacağını ve etkileşime giremeyeceğini göstermiştir.

Hastanelerin kamuya açı web sitelerinin kalitesi ile toplam hasta memnuniyeti puanları arasındaki ilişkiyi araştıran bir çalışmada, ABD'deki 1.952 hastane analiz edilmiş ve sonuçlar web sitesi kalitesinin hastaların seçimi ile anlamlı ve pozitif olarak ilişkili olduğunu göstermiştir. Çalışma, sağlık sektöründe web tabanlı bilgi kaynaklarının tüketici davranışını etkileme potansiyelinin yüksek olduğuna vurgu yapmıştır (Ford vd., 2013, s. 344). 
Birdir ve Buzcu (2014, s. 13) tarafından, JCI akreditasyon belgesine sahip 46 sağlık kuruluşunun web siteleri incelenmiş, hastanelerin, hastalar için önemli bir kriter olan hizmet ücretleri konusunda sitelerinde bilgi vermedikleri görülmüştür.

ABD'deki 2407 hastane web sitesi ile ABD'deki 157 çocuk hastanesinin web siteleri üzerine yapılan çalışmalarda; web siteleri (1) erişilebilirlik, (2) içerik, (3) pazarlama, (4) teknoloji ve (5) kullanılabilirlik olmak üzere beş boyutta incelenmiş, tespit edilen veriler (0-10 puan aralığında), Tablo 1'de verilmiştir (Huerta vd., 2014, s. 4; Huerta vd., 2016, s. 7).

Tablo 1. Hastane web siteleri üzerine yapılan araştırma sonuçları

\begin{tabular}{lcc}
\hline Boyut & $\begin{array}{c}\text { ABD'deki 2407 hastane ve } \\
\text { sağlık sistemi web siteleri } \\
\text { puanları }\end{array}$ & $\begin{array}{c}\text { ABD'deki 157 çocuk } \\
\text { hastanesinin web } \\
\text { siteleri puanları }\end{array}$ \\
\hline Erişilebilirlik & 5.08 & 5.05 \\
İçerik & 6,49 & 8.23 \\
Pazarlama & 5.03 & 6,73 \\
Teknoloji & 4,43 & 5.36 \\
Kullanılabilirlik & 5,16 & 6,13 \\
\hline
\end{tabular}

Salarvand vd. (2016, s. 131), Tahran'daki kamu hastanelerinin web sitelerinin kalitesi üzerine yaptıkları çalışmada, 107 devlet hastanesinden, sadece 59 hastanenin $(\% 55,1)$ aktif ve güncel bir web sitesine sahip olduğunu bulmuşlardır.

\section{MATERYAL VE YÖNTEM}

\subsection{Araştırmanın Amacı}

Araştırmanın amacl; Türkiye' deki üniversite, devlet ve özel hastanelerin kurumsal web sitelerinin; (1) kullanılabilirlik, (2) erişim kalitesi, (3) performans, (4) güncellik, (5) teknik altyapı ve (6) sosyal boyut ana başlıkları üzerinden analiz etmek ve hastanelerin web siteleri aracılı̆̆ıyla kullanıcılara sundukları hizmetlerin kalitesine ilişkin bulgular elde etmektir.

\subsection{Araştırmanın Kapsamı ve Sınırlılıklanı}

Araştırmanın evreni, Türkiye'deki üniversite, devlet ve özel hastane web siteleridir. Araştırmanın örneklemi ise, Marmara, İç Anadolu, Ege ve Akdeniz Bölgelerindeki tüm illerden seçilen 181 adet hastanenin web sitesi ile Güneydoğu Anadolu, Karadeniz ve Doğu Anadolu Bölgelerindeki en çok nüfusa sahip ilk beş ilinden seçilen 71 adet hastanenin web sitesidir.

Araştırma; Marmara, İç Anadolu, Ege ve Akdeniz Bölgelerindeki illerin tamamını, Güneydoğu Anadolu, Karadeniz ve Doğu Anadolu Bölgelerindeki illerin nüfus oranı bakımından en büyük ilk beş ilini kapsamaktadır. Araştırma kapsamında Türkiye'deki 7 
coğrafi bölgeden toplam 252 hastane web sitesi incelenmiştir. Çalışılan 55 ilin toplam nüfusu 2019 yılı itibariyle 73 milyondan fazla olup, bu nüfus oranı ile Türkiye'nin \% 90,8'i çalışma kapsamına alınmıştır. Araştırmada 6 ana başlık altında toplam 22 inceleme kriteri üzerinden analizler yapılmıştır.

Çalışmaya temel oluşturan 6 ana başlık ve 22 kriter bir kısıtlılık oluşturmaktadır. Daha fazla kriterin incelenmesi daha doğru sonuçlara ulaşılabilmesini sağlayabilecektir.

\subsection{Araştırmanın Yöntemi}

Çalışmada ilk olarak Türkiye'deki 7 coğrafi bölgenin illeri ve nüfus oranları belirlenmiştir. İller sıralanırken nüfus oranları dikkate alınmış ve en yüksek nüfuslu ilden en düşük nüfuslu ile doğru sıralama yapılmıştır. Nüfus oranlarına ilişkin bilgiler, Türkiye İstatistik Kurumu'nun web sitesinden alınmıştır. Araştırma kapsamına alınan iller Tablo 2' de verilmiştir.

Tablo 2. Araştırma Kapsamına Alınan İller

\begin{tabular}{ll}
\hline Coğrafi Bölgeler & \multicolumn{1}{c}{ Araştırma Kapsamına Alınan İller } \\
\hline Marmara & $\begin{array}{l}\text { İstanbul, Bursa, Kocaeli, Balıkesir, Tekirdağ, Sakarya, } \\
\text { Çanakkale, Edirne, Kırklareli, Yalova, Bilecik }\end{array}$ \\
İç Anadolu & $\begin{array}{l}\text { Ankara, Konya, Kayseri, Eskişehir, Sivas, Yozgat, Aksaray, } \\
\text { Niğde, Nevşehir, Kırıkkale, Karaman, Kırşehir, Çankırı }\end{array}$ \\
Ege & $\begin{array}{l}\text { İzmir, Manisa, Aydın, Denizli, Muğla, Afyonkarahisar, } \\
\text { Kütahya, Uşak }\end{array}$ \\
Akdeniz & $\begin{array}{l}\text { Antalya, Adana, Mersin, Hatay, Kahramanmaraş, } \\
\text { Osmaniye, Isparta, Burdur }\end{array}$ \\
Güneydoğu Anadolu & Gaziantep, Şanlıurfa, Diyarbakır, Mardin, Adıyaman \\
\hline Karadeniz & Samsun, Trabzon, Ordu, Tokat, Zonguldak \\
\hline
\end{tabular}

Türkiye'nin 7 coğrafi bölgesini kapsayacak şekilde gerçekleştirilen bu çalışma; her bir ilin, varsa iki üniversite hastanesi, iki devlet hastanesi ve bir özel hastanesinin web siteleri üzerinden yapılmıştır. Çok sayıda üniversite hastanesi ve devlet hastanesi olan illerde seçim kriterimiz, kurumların, bulunduğu ilde yatak kapasitesi büyüklüğü bakımından ilk iki sırada yer almaları olmuştur. Özel hastane seçim kriterimiz ise kurumların Google arama motoru 
sıralamasında en önde gelmesi, reytingi en yüksek kurum olmasıdır. Üniversite hastanesinin tek olduğu illerde, iki devlet hastanesi yanında, iki de özel hastane seçilmiştir. Üniversite hastanesinin olmadığı illerde, varsa iki devlet hastanesi ve iki özel hastane seçilmiştir. Hastanelerin tespiti ise T.C. Sağlık Bakanlığı resmi web sitesi ile Üniversitelerin, İl Sağlık Müdürlüklerinin ve Valiliklerin resmi web siteleri üzerinden yapılmıştır.

Çalışma kapsamına alınacak illerin belirlenmesinden sonra, tespit edilen illerdeki hastanelerin kurumsal web siteleri ve adresleri, Google arama motoru vasitasiyla bulunmuştur. Web tarayıcısı olarak Chrome (v. 2018) kullanılmıştır.

Çalışma kriterlerimize uygun olan 256 hastanenin kurumsal web siteleri üniversite, devlet ve özel hastane olarak sınıflandırılmış, kuruluş yılları ve yatak sayıları tespit edilerek kayıt altına alınmıştır. Belirlenen 256 hastane içinden; 3 üniversite hastanesi ve 1 özel hastane web sitesi, altyapıları ve kullanılan teknoloji nedeniyle sağlıklı şekilde analiz edilememiş ve kapsam dışı bırakılmıştır. Toplam 252 adet hastane web sitesi analiz edilmiştir.

\subsection{Verilerin Analiz Biçimi}

Hastane web siteleri, Arama Motoru Optimizasyonu (Search Engine Optimization) algoritmasını kullanan “Nibbler" web sitesi raporlama yazılımı aracılığıyla, Ekim 2018- Ocak 2019 tarihleri arasında analiz edilmiştir. Nibbler, web sitelerini farklı algoritmalar kullanarak çok çeşitli alanlarda test ederek uluslararası kriterlere göre puanlama yapabilen bir yazılımdır. Tüm dünyada kamu ve özel kurumlar web sitelerinin kullanılabilirlik, erişim kalitesi, erişim ve cevap verebilme performansı, güncelliği, teknik altyapısı gibi birçok alanda bu yazılımı kullanmaktadır. Yazılım web sitelerinin eksi ve geliştirilmesi gereken yönlerini çok detaylı şekilde analiz edebilmektedir. Sunduğu açık ve anlaşılır raporlar ile kurumların daha kaliteli, daha etkili ve kullanıcı dostu web siteleri oluşturabilmeleri noktasında önemli katkılar sağlamaktadır.

Bu çalışmada, araştırma kapsamına alınan üniversite, devlet ve özel hastanelerin web siteleri kullanılabilirlik, erişim kalitesi, performans, güncellik, teknik altyapı ve sosyal boyut açısından Nibbler yazılımı kullanılarak incelenmiştir.

Analiz kriterlerimiz aşağıda verilmiştir:

(1) Genel Puan, (2) Erişilebilirlik, (3) Deneyim, (4) Pazarlama, (5) Teknoloji, (6) Erişim ve Cevap Alma Hızı, (7) Popülerlik, (8) Sosyal İlgi, (9) Facebook Sayfası Kullanımı, (10) Twitter, (11) Mobilite, (12) Fotoğraf ve Görüntüler, (13) Ana Başlıklar, (14) Sayfa Başlıkları, (15) İç Bağlantılar, (16) Gelen Bağlantılar, (17) Bilgi İçeriği Miktarı, (18) Meta Etiketleri, (19) URL Biçimi, (20) Yazdırılabilirlik, (21) Analiz ve (22) Güncellik.

1. Genel Puan: Analizi yapılan hastane web sitesinin toplam puanını ifade etmektedir. 
2. Erişilebilirlik: Hastane web sitesinin, sabit hat üzerinden ve mobil cihazlar vasıtasıyla farklı tarayıcılar ve işletim sistemleri üzerinden ne kadar erişilebilir olduğu göstermektedir.

3. Deneyim: Hastane web sitesinin kullanıcılar için görsel açıdan ve içerik yönünden ne kadar tatmin edici olduğunu göstermektedir.

4. Pazarlama: Hastane web sitesinin e-pazarlama teknikleri açısından aldığı puanı göstermektedir.

5. Teknoloji: Web sitesinin teknolojik açıdan ne kadar iyi tasarlandığını ve inşa edildiğini göstermektedir.

6. Erişim ve Cevap Alma Hızı: Hastane web sitesinin erişim ve cevap alma hızını ve kalitesini göstermektedir.

7. Popülerlik: Hastane web sitesinin dünya genelindeki popülerlik düzeyini göstermektedir.

8. Sosyal İlgi: Hastane web sitesinin sosyalite seviyesini göstermektedir.

9. Facebook Sayfası Kullanımı: Hastane web sitesinin Facebook bağlantısı içerip içermediğini ve Facebook sayfasıyla ne kadar ilişkili olduğunu göstermektedir.

10. Twitter: Hastane web sitesinin Twitter bağlantısı içerip içermediğini ve Twitter sayfasıyla ne kadar ilişkili olduğunu göstermektedir.

11. Mobilite: Hastane web sitesinin; cep telefonu, tablet bilgisayar ve diğer mobil cihazlardan görüntülemek için optimize edilme düzeyini göstermektedir.

12. Fotoğraf ve Görüntüler: Hastane web sitesinde yer alan fotoğraf ve görüntülerin varlığı, boyutlandırılma oranının kalitesi ve güncelliğini göstermektedir.

13. Ana Başlıklar: Hastane web sitesindeki tanımlanmış ana başlıkların aktif olup olmadığını ve kullanım miktarlarını göstermektedir.

14. Sayfa Başlıkları: Hastane web sitesindeki tanımlanmış ana sayfalar altındaki başlıkların aktif olup olmadığını ve kullanım miktarlarını göstermektedir.

15. İç Bağlantılar: Hastane web sitesi sayfalarında bulunan bağlantıların (linklerin) erişim kalitesini göstermektedir.

16. Gelen Bağlantılar: Hastane web sitesine bağlantı veren ve alan sayfaların hacim ve kalite düzeyini göstermektedir. 
17. Bilgi İçeriği Miktarı: Hastane web sitesinin sayfa başına düşen kelime miktarının ortalama düzeyini göstermektedir.

18. Meta Etiketleri: Hastane web sitesinin arama motorlarında görünüşünün kalite seviyesini ifade etmektedir.

19. URL Biçimi: Hastane web sitesi adresinin kalitesi ve verimlilik düzeyini göstermektedir.

20. Yazdırılabilirlik: Hastane web sitesi sayfalarının baskı (print) için optimize edilme düzeyini göstermektedir.

21. Analiz: Hastane web sitesinin, ziyaretçi davranışlarını takip eden ve inceleyen analiz yazılımları kullanılıp kullanmadığını ve kalitesini göstermektedir.

22. Güncellik: Hastane web sitesinin en son güncelleme yapılan tarihine göre güncel olma durumunu göstermektedir.

Çalışmaya dâhil edilen hastanelerin kurumsal web siteleri, arama motoru optimizasyonu algoritmasını kullanan Nibbler yazılımı aracılığıyla analiz edilmiştir. Kriterler; analiz yazılımı tarafından 0-10 puan aralığında puanlandırılmıştır. Bir web sitesinin bir kriter için aldığ 10 puan çok iyi anlamına gelmekle birlikte, alınan puan düştükçe söz konusu kriter açısından iyileştirilmeye muhtaç anlamına gelmektedir. Literatürde bu yazılımı kullanarak analiz yapan bir araştırmaya rastlanılmamakla birlikte, bu çalışmada 7 puan ve üzeri alan kriterler başarılı olarak nitelendirilmiştir. Elde edilen bulgular ortak bir veri tabanında birleştirilmiştir.

\section{BULGULAR}

\subsection{Hastane Türleri ve Yatak Sayısı Aralıkları}

Çalışmaya dâhil edilen hastaneler; üniversite, devlet ve özel olarak türlerine göre sınıflandırılmış ve coğrafi bölgelere göre yapılan dağılım Tablo 3'te verilmiştir. Kapsama alınan hastanelerin; 57'si üniversite hastanesi (\%22,62), 109'u devlet hastanesi $(\% 43,25)$ ve $86^{\prime}$ s1 $(\% 34,13)$ ise özel hastane türündedir.

Tablo 3. Hastane Türlerinin Bölgelere Göre Dağılımı

\begin{tabular}{|c|c|c|c|c|c|c|c|c|}
\hline \multirow[b]{2}{*}{$\begin{array}{c}\text { Hastane } \\
\text { Türü }\end{array}$} & \multicolumn{7}{|c|}{ Coğrafi Bölgeler } & \multirow{2}{*}{$\begin{array}{l}\tilde{c} \\
\frac{\pi}{2} \\
0 \\
\theta\end{array}$} \\
\hline & Marmara & $\begin{array}{c}\text { İç } \\
\text { Anadolu }\end{array}$ & Ege & Akdeniz & $\begin{array}{l}\text { Güneydoğu } \\
\text { Anadolu }\end{array}$ & Karadeniz & $\begin{array}{c}\text { Doğu } \\
\text { Anadolu }\end{array}$ & \\
\hline Üniversite & 10 & 13 & 9 & 7 & 6 & 5 & 7 & 57 \\
\hline Devlet & 22 & 25 & 16 & 16 & 10 & 10 & 10 & 109 \\
\hline Özel & 17 & 18 & 14 & 14 & 8 & 8 & 7 & 86 \\
\hline
\end{tabular}


Araştırma kapsamına alınan toplam 252 hastanenin yatak sayısı oranları sinıflandırılmış; 66 adet hastanenin (\%26,19) "1-99" yatak sayısı aralığında, 92 adet hastanenin (\%36,51) "100-399" yatak sayısı aralığında, 85 adet hastanenin ise $(\% 33,73)$ "400 ve üstü" yatak sayısı aralığında olduğu belirlenmiştir. Yatak sayısı tespit edilemeyen hastane sayısı ise $9(\% 3,57)^{\prime}$ dur.

Tablo 4. Bölgelere Göre Hastane Yatak Sayısı Aralıkları

\begin{tabular}{|c|c|c|c|c|c|c|c|c|}
\hline \multirow[b]{2}{*}{$\begin{array}{c}\text { Yatak } \\
\text { Sayısı } \\
\text { Aralıkları }\end{array}$} & \multicolumn{7}{|c|}{ Coğrafi Bölgeler } & \multirow[b]{2}{*}{$\frac{\pi}{\frac{\pi}{2}}$} \\
\hline & Marmara & $\begin{array}{c}\text { İç } \\
\text { Anadolu }\end{array}$ & Ege & Akdeniz & $\begin{array}{c}\text { Güneydoğu } \\
\text { Anadolu }\end{array}$ & Karadeniz & $\begin{array}{c}\text { Doğu } \\
\text { Anadolu }\end{array}$ & \\
\hline $1-99$ & 11 & 20 & 8 & 10 & 4 & 5 & 8 & 66 \\
\hline 100-399 & 19 & 17 & 18 & 11 & 12 & 11 & 4 & 92 \\
\hline 400 ve üstü & 18 & 16 & 13 & 15 & 6 & 7 & 10 & 85 \\
\hline $\begin{array}{c}\text { Tespit } \\
\text { Edilemeyen }\end{array}$ & 1 & 3 & - & 1 & 2 & - & 2 & 9 \\
\hline
\end{tabular}

\subsection{Bölgelerin Kriterlere Göre Puanları}

Genel puan kriterinde en yüksek puanı alan bölgenin 7,4 puanla Marmara Bölgesi olduğu, en düşük puanı alan bölgenin ise 6,9 puanla İç Anadolu Bölgesi olduğu görülmektedir. Genel Puan kriterinin bölgeler bazında ortalaması ise 7,2 puan olarak tespit edilmiştir.

Erişilebilirlik kriterinde, en yüksek puanı alan bölge 8,5 puanla Marmara Bölgesi iken, en düşük puanı alan bölge 8,0 puanla İç Anadolu Bölgesidir. Erişilebilirlik kriterinin bölgeler bazında puan ortalaması ise 8,3 olarak tespit edilmiştir.

Deneyim kriterinde, en yüksek puanı alan bölge 6,8 ile Ege Bölgesi iken, en düşük puanı alan bölge 6,3 ile İç Anadolu Bölgesidir. Deneyim kriterinin bölgeler bazında puan ortalaması ise 6,5 olarak tespit edilmiştir.

Pazarlama kriterinde en yüksek puanı alan bölgenin 5,1 puanla Güney Doğu Anadolu Bölgesi olduğu, en düşük puanı alan bölgenin ise 4,6 puanla İç Anadolu Bölgesi olduğu görülmektedir. Pazarlama kriterinin bölgeler bazında puan ortalaması 4,8 olarak tespit edilmiştir.

Teknoloji kriterinde, en yüksek puanı alan bölgeler 7,9 puanıla Marmara ve Doğu Anadolu Bölgeleri olmuştur. En düşük puanı alan bölgenin ise 7,3 puanla Güneydoğu Anadolu Bölgesi olduğu görülmektedir. Deneyim kriterinin bölgeler bazında puan ortalaması ise 7,7 olarak tespit edilmiştir. 
Erişim ve Cevap Alma Hızı kriterinde, en yüksek puanı alan bölge 6,5 ile Doğu Anadolu Bölgesi iken, en düşük puanı alan bölge 5,9 ile Akdeniz Bölgesi olmuştur. Erişim ve Cevap Alma Hızı kriterinin bölgeler bazında puan ortalaması ise 6,2 olarak tespit edilmiştir.

Popülerlik kriterinde en yüksek puanı alan bölge 3,4 puanla Karadeniz Bölgesi iken, en düşük puanı alan bölge 2,4 ile Doğu Anadolu Bölgesi olmuştur. Popülerlik kriterinin bölgeler bazında puan ortalaması ise 3,1 olarak tespit edilmiştir.

Sosyal İlgi kriterinde, en yüksek puanı alan bölge 5,1 puanla Güneydoğu Anadolu Bölgesi iken, en düşük puanı alan bölgeler 4,4 ile İç Anadolu ve Akdeniz olmuştur. Sosyal İlgi kriterinin bölgeler bazında puan ortalaması ise 4,6 olarak tespit edilmiştir.

Facebook sayfası kullanımı kriterinde, en yüksek puanı alan bölgelerin 3,3 puanla Ege ve Güneydoğu Anadolu Bölgeleri olduğu, en düşük puanı alan bölgenin ise 1,8 puanla İç Anadolu Bölgesi olduğu görülmektedir. Facebook Sayfası Kullanımı kriterinin bölgeler bazında puan ortalaması ise 2,5 olarak tespit edilmiştir.

Twitter kriterinde, en yüksek puanı alan bölge 1,9 ile Marmara Bölgesi iken, en düşük puanı alan bölge 0,4 puanla Doğu Anadolu Bölgesi olmuştur. Twitter kriterinin bölgeler bazında puan ortalaması ise 1,3 olarak tespit edilmiştir.

Mobilite kriterinde, en yüksek puanı alan bölgeler 9,5 puan ile Ege ve Doğu Anadolu Bölgeleri iken, en düşük puanı alan bölge 8,3 puanla Karadeniz Bölgesi olmuştur. Mobilite kriterinin bölgeler bazında puan ortalaması ise 8,9 olarak tespit edilmiştir.

Fotoğraf ve Görüntüler kriterinde, en yüksek puanı alan bölgeler 9,6 puanla İç Anadolu, Akdeniz ve Doğu Anadolu Bölgeleri iken, en düşük puanı alan bölgelerin 9,4 puanla Marmara, Ege ve Güneydoğu Anadolu Bölgeleri olmuştur. Fotoğraf ve Görüntüler kriterinin bölgeler bazında puan ortalaması ise 9,5 olarak tespit edilmiştir.

Ana Başlıklar kriterinde, en yüksek puanı alan bölge 6,7 ile Marmara Bölgesi iken, en düşük puanı alan bölge 4,7 ile Karadeniz Bölgesi olmuştur. Ana Başlıklar kriterinin bölgeler bazında puan ortalaması ise 5,5 olarak tespit edilmiştir.

Sayfa Başlıkları kriterinde, en yüksek puanı alan bölgenin 10 puanla Güneydoğu Anadolu Bölgesi olduğu, en düşük puanı alan bölgenin ise 9,7 puanla İç Anadolu Bölgesi olduğu görülmektedir. Sayfa Başlıkları kriterinin bölgeler bazında puan ortalaması ise 9,9 olarak tespit edilmiştir.

İç Bağlantılar kriterinde, en yüksek puanı alan bölge 8,4 ile Karadeniz Bölgesi iken, en düşük puanı alan bölgeler 7,7 puanla İç Anadolu ve Ege Bölgeleri olmuştur. İç Bağlantılar kriterinin bölgeler bazında puan ortalaması ise 8,0 olarak tespit edilmiştir. 
Gelen Bağlantılar kriterinde, en yüksek puanı alan bölge 8,2 ile Karadeniz Bölgesi iken, en düşük puanı alan bölge 6,4 ile Doğu Anadolu Bölgesi olmuştur. Gelen Bağlantılar kriterinin bölgeler bazında puan ortalaması ise 7,5 olarak tespit edilmiştir.

Bilgi İçeriği Miktarı kriterinde, en yüksek puanı alan bölgelerin 6,8 puanla Marmara ve Karadeniz Bölgeleri olduğu, en düşük puanı alan bölgenin ise 6,3 puanla Akdeniz Bölgesi olduğu görülmektedir. Bilgi İçeriği Miktarı kriterinin bölgeler bazında puan ortalaması ise 6,6 olarak tespit edilmiştir.

Meta Etiketleri kriterinde, en yüksek puanı alan bölge 7,9 ile Ege Bölgesi iken, en düşük puanı alan bölgeler 6,5 ile Güneydoğu Anadolu ve Karadeniz Bölgeleri olmuştur. Meta Etiketleri kriterinin bölgeler bazında puan ortalaması ise 7 olarak tespit edilmiştir.

URL Biçimi kriterinde, en yüksek puanı alan bölge 7,0 puanla Karadeniz Bölgesi iken, en düşük puanı alan bölgenin 6,1 ile Doğu Anadolu Bölgesi olmuştur. URL Biçimi kriterinin bölgeler bazında puan ortalaması ise 6,5 olarak tespit edilmiştir.

Yazdırılabilirlik kriterine bakıldığında, en yüksek puanı alan bölgelerin 8,6 puanla Marmara ve Ege Bölgeleri olduğu, en düşük puanı alan bölgenin ise 5,7 puanla Karadeniz Bölgesi olduğu görülmektedir. Yazdırılabilirlik kriterinin bölgeler bazında puan ortalaması ise 7,7 olarak tespit edilmiştir.

Analiz kriterinde, en yüksek puanı alan bölge 8,7 ile Marmara Bölgesi iken, en düşük puanı alan bölge 7,0 ile Akdeniz Bölgesi olmuştur. Analiz kriterinin bölgeler bazında puan ortalaması ise 7,7 olarak tespit edilmiştir.

Güncellik kriterinde elde edilen sonuçlara bakıldığında, en yüksek puanı alan bölgenin 7,4 puanla Karadeniz Bölgesi olduğu, en düşük puanı alan bölgelerin ise 6,3 ile Akdeniz ve Güney Doğu Anadolu Bölgeleri olduğu görülmektedir. Güncellik kriterinin bölgeler bazında puan ortalaması ise 6,8 olarak tespit edilmiştir.

\subsection{Bölgelerin Kriter Puan Ortalamaları}

Araştırma kapsamına alınan hastane web sitelerinin kriter puanlarının, 7 coğrafi bölge bazında elde edilen ortalamaları Grafik 1'de verilmiştir. 


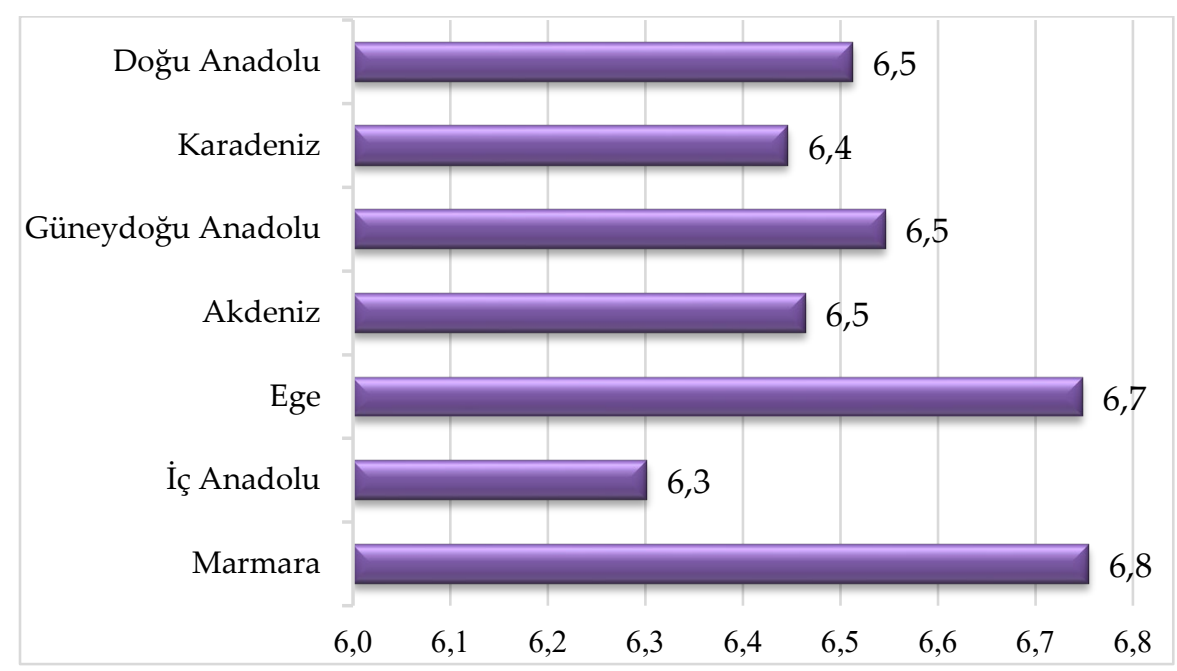

Grafik 1. Bölgelere Göre Kriter Puan Ortalamaları

Bölgeler bazında kriter puanlarının ortalamalarına bakıldı̆̆ında (Grafik 1), en yüksek ortalamaya sahip bölgenin 6,8 ortalama puanla Marmara Bölgesi olduğu, en düşük ortalamaya sahip bölgenin ise, 6,3 ortalama puanla İç Anadolu Bölgesi olduğu görülmektedir.

\subsection{Türkiye Geneline Göre Kriter Puanları}

Araştırma kapsamına alınan hastane web sitelerinin kriter puanlarının, Türkiye genelinde elde edilen ortalamaları Grafik 2' de verilmiştir.

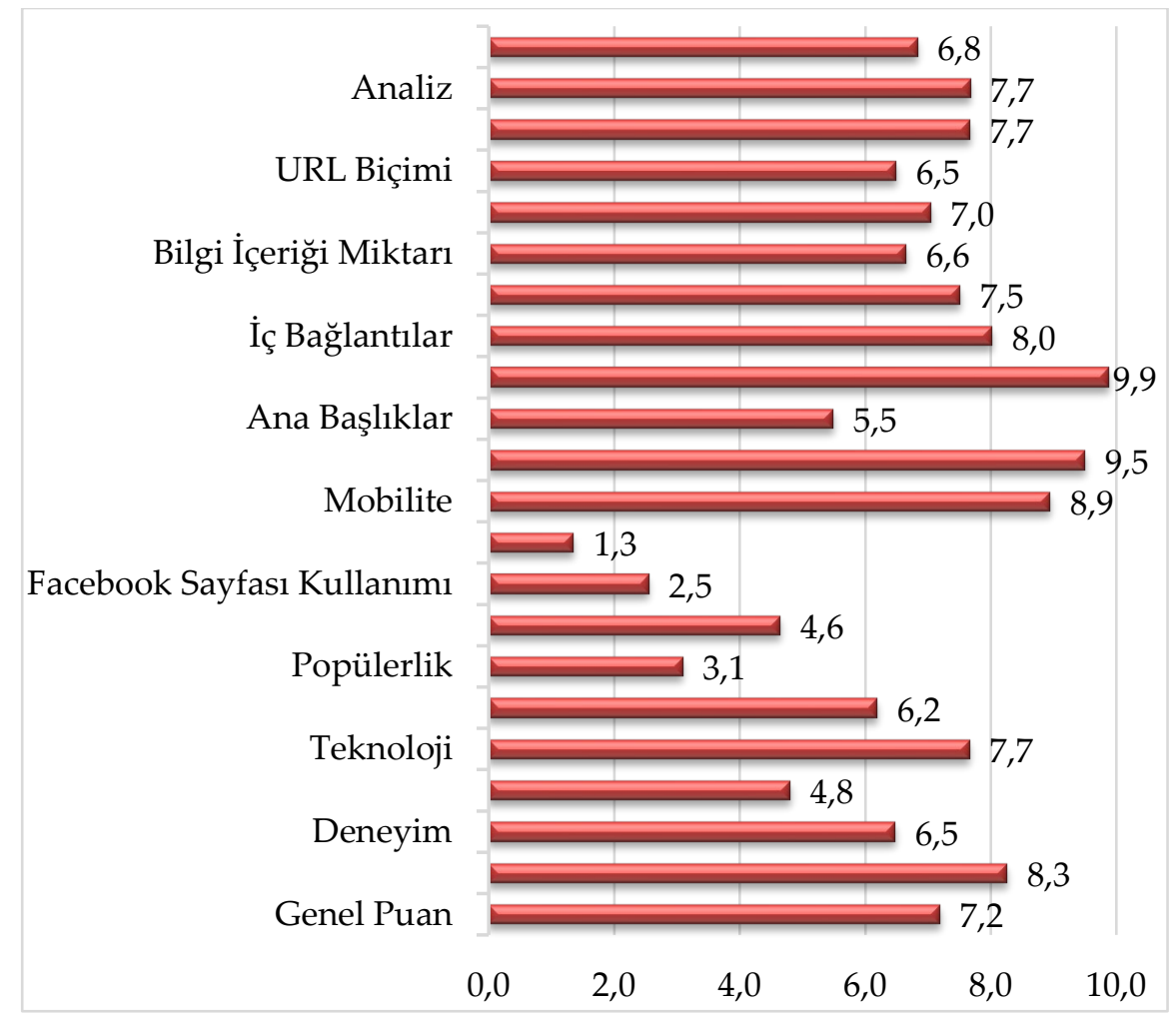

Grafik 2. Türkiye Geneline Göre Kriter Puanları 
Grafik 2'de verilen Türkiye geneli kriterlerin puan ortalamalarına bakıldığında, en yüksek puanı alan kriter 9,9 ortalama puanla Sayfa Başlıkları kriteridir. En düşük puanı alan kriter, 1,3 ortalama puanla Twitter olmuştur. Tüm kriter puanlarının Türkiye ortalamasının ise (Ek 1) 6,5 puan olduğu tespit edilmiştir. Bu bulgu, Türkiye'deki hastane web sitelerinin kalite, güncellik ve tasarım alt yapısı bakımından ortalama puanıdır.

\section{SONUÇ VE ÖNERILER}

Araştırma sonucunda, en yüksek puan ortalamasına sahip olduğu tespit edilen bölge, nüfus yoğunluğu bakımından en büyük coğrafi bölge olan Marmara Bölgesi (6,8)'dir. Diğer bölgelerin aldığı ortalama puanlar ile başarı sıralaması şöyledir; Ege Bölgesi (6,7), Akdeniz Bölgesi (6,5), Güneydoğu Anadolu Bölgesi (6,5), Doğu Anadolu Bölgesi (6,5), Karadeniz Bölgesi $(6,4)$ ve İç Anadolu Bölgesi (6,3).

Türkiye genelinde tüm analiz kriterlerinin puan ortalamaları alınarak, Türkiye'deki hastane web sitelerinin en başarılı olduğu kriterler ile düşük puan alarak istenilen verimlilikte olmayan kriterler tespit edilmiştir (Ek 1). Buna göre, Türkiye'deki hastane web sitelerinin en başarılı oldukları kriterler ve aldıkları ortalama puanlar sırasıyla Tablo 5'te verilmiştir.

Tablo 5. Türkiye' deki Hastane Web Sitelerinin En Başarılı Oldukları Kriterler ve Aldıkları Ortalama Puanlar

\begin{tabular}{lc}
\hline \multicolumn{1}{c}{$\begin{array}{c}\text { Türkiye'deki Hastane Web Sitelerinin } \\
\text { En Başarılı Oldukları Kriterler }\end{array}$} & $\begin{array}{c}\text { Aldıkları Ortalama } \\
\text { Puanlar }\end{array}$ \\
\hline Sayfa Başlıkları & 9,9 \\
Fotoğraf ve Görüntüler & 9,5 \\
Mobilite & 8,9 \\
Erişilebilirlik & 8,3 \\
İç Bağlantılar & 8,0 \\
Teknoloji & 7,7 \\
Yazdırılabilirlik & 7,7 \\
Analiz & 7,7 \\
Gelen Bağlantılar & 7,5 \\
Genel Puan & 7,2 \\
Meta Etiketleri & 7,0 \\
\hline
\end{tabular}

Türkiye'deki hastane web sitelerinin düşük puan aldıkları kriterler ve ortalama puanları sırasıyla Tablo 6' da verilmiştir. 
Tablo 6. Türkiye' deki Hastane Web Sitelerinin Düşük Puan Aldıkları Kriterler ve Ortalama Puanları

\begin{tabular}{lc}
\hline \multicolumn{1}{c}{$\begin{array}{c}\text { Türkiye'deki Hastane Web Sitelerinin } \\
\text { Düşük Puan Aldıkları Kriterler }\end{array}$} & $\begin{array}{c}\text { Aldıkları Ortalama } \\
\text { Puanlar }\end{array}$ \\
\hline Güncellik & 6,8 \\
Bilgi İçeriği Miktarı & 6,6 \\
\hline Deneyim & 6,5 \\
URL Biçimi & 6,5 \\
Erişim ve Cevap Alma Hızı & 6,2 \\
Ana Başlıklar & 5,5 \\
Pazarlama & 4,8 \\
Sosyal İlgi & 4,6 \\
Popülerlik & 3,1 \\
Facebook Sayfası Kullanımı & 2,5 \\
Twitter & 1,3 \\
\hline
\end{tabular}

Sonuçlardan da görüldüğü üzere, hastane web sitelerinin popülerlik, sosyal ilgi, Facebook ve Twitter gibi önemli kriterlerden aldıkları puanlar oldukça düşük çıkmıştır. Sosyal medyanın önemli ve etkileyici gücü düşünüldüğünde bu oranlar ile paydaşlara ulaşabilme ve kalıcı bir imaj oluşturulabilmesi zor olabilecektir. Türkiye'de 52 milyon kişinin (\%63) aktif sosyal medya kullanıcısı olduğu (wearesocial.com) düşünüldüğünde, kurumların kullanıcılara bu yolla doğrudan, ucuz ve etkili şekilde erişebilmeleri mümkün olabilecektir. Sosyal medya araçları, hastanelerin paydaşları ile olan iletişimlerinin interaktif olarak gerçekleştirmesi imkânını da sunmaktadır. Hastaneler, web sitelerinde yer verdikleri Facebook, Twitter, Youtube ve Instagram gibi sosyal medya araçlarıyla hastaların talep ettiği güvenilir ve her an erişilebilir bir sağlık iletişimi gerçekleştirme olanağına fırsat vermiş olacaklardir.

Türkiye' deki hastane web sitelerinde, tanımlanmış ana sayfalar altındaki başlıkların aktif olduğu ve kullanım miktarlarının oldukça yüksek olduğu saptanmıştır. Sayfa başlıkları, siteyi ziyaret ederken, arama sonuçlarında ve tarayıcı penceresinin en üstünde görünmektedir. Sitelerde, fotoğraf ve görüntülerin kullanım oranlarının yüksek olduğu ve bunların boyutlandırılma oranının kaliteli olduğu tespit edilmiştir. Hastane web sitelerinin cep telefonu, tablet bilgisayar ve diğer mobil cihazlardan görüntülenebilmesi için optimize edilmiş durumda olduğu, web sitelerine mobil cihazlar vasıtasıyla farklı tarayıcılar ve işletim sistemleri üzerinden erişilebilme imkânının yüksek olduğu görülmektedir. Hastane web sitesi sayfalarında bulunan bağlantıların (linklerin) erişim kalitesinin yüksek, hastane web sitesine bağlantı veren ve alan sayfaların kalite düzeyinin iyi derecede olduğu tespit edilmiştir. Gelen bağlantıların hacim ve kalitesi, bir web sitesinin arama motoru sıralamasını etkilediğinden, bu durum hastaların ilgili hastane web sitelerine kolay ve rahat ulaşabildiği anlamına gelmektedir. 
Web sitelerinin çoğunluğunun sayfaları baskı (print) için optimize edilmiş durumdadır. Hastane web sitelerinin çoğunun arama motorlarında kaliteli bir görünüş sergilediği ve ziyaretçi davranışlarını takip eden ve inceleyen analiz yazılımları kullanım oranının yüksek olduğu tespit edilmiştir. Hastane web sitelerinin büyük bir bölümünün teknolojik açıdan iyi tasarlandığı ve inşa edildiği görülmektedir.

Türkiye'deki hastane web sitelerinin, en son güncelleme yapılan tarihine göre güncel olma durumlarının yeterli seviyede olmadığı saptanmıştır. Bu, kurum imajı için olumsuz bir durumdur çünkü ziyaretçiler güncel web sitelerini daha güvenilir olarak algılamaktadır. Ayrıca düzenli olarak güncellenen web siteleri arama motorları tarafından daha sık incelenmekte, aramalarda ön sıralarda konum almaktadır.

Analiz edilen hastaneler web sitesi adreslerinin kalite ve verimlilik düzeyi olması gerekenden düşük çıkmış, erişim ve cevap alma hızı ve kalitesi yine düşük bulunmuştur. Benzer şekilde, hastane web sitelerinin, kullanıcılar için içerik yönünden tatmin edici olma düzeyinin düşük olduğu tespit edilmiştir. Hastane web sitelerinde sayfa başına düşen kelime miktarı düzeyinin yani bilgi içeriği miktarının yeterli olmadığı, sitedeki tanımlanmış ana başlıkların aktif olma durumunun düşük olduğu saptanmıştır. Bu bir web sitesi için doğru tanımlanmış başlıklar erişilebilirliğe yardımcı olacaktır ve uygun sayfa başlıkları kullanıcıların kolay erişimi için özellikle önemlidir. Genel olarak hastane web sitelerinin e-pazarlama teknikleri açısından aldığı puanların düşük olduğu tespit edilmiştir.

Araştırmada, Türkiye'deki hastane web sitelerinin sosyalite seviyesi orta düzeyde bulunmuş ve söz konusu web sitelerinin dünya genelindeki popülerlik düzeyi düşük çıkmıştır. Hastane web sitelerinin çok azının Facebook ve Twitter bağlantısı içerdiği, çoğunun bu bağlantıları içermediği veya bağlantı içerse dahi bağlantıların Facebook ve Twitter sayfasıyla ilişkilendirilmemiş ve herkese açık düzeyde olmadığı tespit edilmiştir.

Bu çalışmada, özel hastane web sitelerinin, işleyiş kalitesi, güncellik ve tasarım altyapısı bakımından kamu kurumlarına ait web sitelerine göre daha başarılı oldukları, özellikle özel sağlık grubu bünyesindeki hastanelerin web sitelerinin oldukça kaliteli durumda olduğu tespit edilmiştir. Bölgenin veya ilin nüfus yoğunluğu ile hastanelerin yatak sayısının, kriter puanın yüksekliğine veya düşüklüğüne önemli bir etkisi olmadığı saptanmıştır.

Yapılan analizler neticesinde, 22 kritere ilişkin ortalama puanı, söz konusu ilde en yüksek olan hastanenin genellikle özel hastane olduğu, akabinde üniversite hastanelerinin geldiği görülmüştür. 22 kriterin herhangi birine ilişkin o ildeki en yüksek ortalama puanı alan devlet hastanesinin bulunmadığı belirlenmiştir.

Sonuç olarak, incelenen hastane web sitelerinde çeşitli kriterlerde memnun edici sonuçlar olmakla birlikte, bazı kalite unsurlarında eksiklikler olduğu görülmektedir. Özellikle, 
web sitelerinin güncel olma durumlarının devamlı kontrol edilmesi, görsel açıdan ve içerik yönünden kullanıcıları memnun edecek kaliteli bir web sitesi tasarımı yapılması, siteye erişim ve cevap alma hızının arttırılmasına yönelik çalışmalar yapılması, e-pazarlama tekniklerine gereken önemin verilerek geliştirilmesi, düşük olarak tespit edilen kriterlerin yükseltilebilmesi için önemli hususların başında gelmektedir. Hastanelerin kurumsal web sitelerinde, popülerliği arttıracak uygulamalara yer vermeleri ve web sitesinin sosyal medya hesapları ile ilişkilendirildiği bağlantılar içermesi sağlık hizmeti alanlar açısından faydalı olabilecektir.

Uluslararası kriterler göz önüne alınarak inşa edilmiş kullanışlı bir web sitesi; kullanıcıların dikkatini ve ilgisini çekecek, hastane imajına olumlu birçok katkı sunacak, tüketicilerin ilgili kurumu tekrar tercih etmesi ve etrafındaki kişilere önermesi noktasında faydalı olabilecek, reklam ve tanınırlık konularında hem maliyet hem de zaman tasarrufu sağlayabilecektir.

$\mathrm{Bu}$ araştırmanın, özel ve kamu hastane yöneticilerinin kurumsal web sitelerinde bulunması gereken özelliklere ilişkin bilgi ve istatistik sağlama noktasında ve araştırma neticesinde elde edilen sonuçların eksikliklerin giderilmesinde faydalı olacağı düşünülmektedir. Literatüre katkı sunması amacıyla ileride yapılması muhtemel çalışmalarda; kriter sayısının artırılarak daha fazla sayıda veri elde edilebilecek analizlerin yapılması, dünyada önde gelen sağlık kurumları ile karşılaştırmalı analizlere yer verilmesi önerilmektedir.

\section{KAYNAKÇA}

Alba-Ruiz, R. Bermúdez-Tamayo, C. Pernett, JJ. Garcia-Gutierrez, JF. Cózar-Olmo, JM. Valero-Aguilera, B. (2013). Adapting The Content of Cancer Web Sites to The Information Needs of Patients: Reliability and Readability. Telemedicine and e-Health, 19(12), 956-966. DOI: 10.1089/tmj.2013.0050

Ardıç Çobaner, A. Köksoy, S. (2014). Sağlık Alanında Sosyal Medyanın Kullanımı: Twitter'da Sağlık Mesajları. Akademik Bilişim'14, 5-7.

Başak, F. Başak, S. Öztürk, K. (2006). Devlet Hastaneleri Web Sitelerinin Değerlendirilmesi. V. Uluslararası Katılımlı Tıp Bilişimi Kongresi, 13-16.

Birdir, K. Buzcu, Z. (2014). JCI Akreditasyon Belgesine Sahip Olan Sağlik Kuruluşlarının WEB Sitelerinin Medikal Turizm Açısından Değerlendirilmesi. Çă̆ Üniversitesi Sosyal Bilimler Dergisi, 11(1), 1-19.

Chen, M. (2018). Improving Website Structure Through Reducing Information Overload. Decision Support Systems, 110, 84-94. DOI: 10.1016/j.dss.2018.03.009

Dunne, S. Cummins, N.M. Hannigan, A. Shannon, B. Dunne, C. Cullen, W. (2013). A Method for the Design and Development of Medical or Health Care Information Websites to Optimize Search Engine Results Page Rankings on Google. Journal of Medical Internet Research, 15(8), 1-8. DOI: 10.2196/jmir.2632 
Onay Durdu, P, Altuntaş, Z. (2020). The Perception of Website Accessibility: A Survey of Turkish Software Professionals. AJIT-e: Bilişim Teknolojileri Online Dergisi, 11 (41), 42-71. DOI:10.5824/ajite.2020.02.003.x

Durmuş, S. Çağıltay, K. (2012). Kamu Kurumu Web Siteleri ve Kullanılabilirlik. E-Devlet Kamu Yönetimi ve Teknoloji İlişkisinde Güncel Gelişmeler, 293-322.

Ford, E.W. Huerta, T.R. Schilhavy, R.A. Menachemi, N. (2012). Effective US Health System Websites: Establishing Benchmarks and Standards for Effective Consumer Engagement. Journal of Healthcare Management, 57(1), 47-65.

Ford, E.W. Huerta, T.R. Diana, ML. Kazley, A.S. Menachemi, N. (2013). Patient Satisfaction Scores and Their Relationship to Hospital Website Quality Measures. Health Marketing Quarterly, 30(4), 334-348. DOI: $10.1080 / 07359683.2013 .844041$

Gallant, L. Irizarry, C. Kreps, G.L. (2007). User-Centric Hospital Web Sites: A Case for Trust and Personalization. E-Service Journal, 5(2), 5-26.

Gruca, T.S. Wakefield, D.S. (2004). Hospital Web Sites: Promise and Progress. Journal of Business Research, 57(9), 1021-1025. DOI: 10.1016/S0148-2963(02)00349-1

Huang, E. (2015). Building a Patient-Centered Hospital Web Site: Best Practices in China. Studies in Health Technology and Informatics, 209, 27-37. DOI: 10.3233/978-1-61499-505-0-27

Huang, E. Angela Chang, C.C. Khurana, P. (2012). Users' Preferred Interactive E-Health Tools on Hospital Web Sites. International Journal of Pharmaceutical and Healthcare Marketing, 6(3), $215-229$. DOI: $10.1108 / 17506121211259395$

Huerta, T.R. Hefner, J.L. Ford, EW. McAlearney, A.S. Menachemi, N. (2014). Hospital Website Rankings in The United States: Expanding Benchmarks and Standards for Effective Consumer Engagement. Journal of Medical Internet Research, 16(2), e64. DOI: 10.2196/jmir.3054

Huerta, T.R. Walker, D.M. Ford, E.W. (2016). An Evaluation and Ranking of Children's Hospital Websites in The United States. Journal of Medical Internet Research, 18(8), e228. DOI: 10.2196/jmir.5799

İleri, Y.Y. (2018). Să̆lık Yönetim Bilişim Sistemleri. Çizgi Kitabevi, Konya.

Kind, T. Wheeler, K.L. Robinson, B. Cabana, M.D. (2004). Do The Leading Children's Hospitals Have Quality Web Sites? A Description of Children's Hospital Web Sites. Journal of Medical Internet Researc, 6(2), e20. DOI: 10.2196/jmir.6.2.e20

Liu, X. Bao, Z. Liu, H. Wang, Z.(2011). The Quality and Characteristics of Leading General Hospitals' Websites in China. Journal of Medical Systems, 35(6), 1553-1562. DOI: 10.1007/s10916-010-9432-0

Llinás, G. Rodríguez-Iñesta, D. Mira, J.J. Lorenzo, S. Aibar, C. (2008). A Comparison of Websites from Spanish, American and British Hospitals. Methods Inf Med, 47(02), 124-130. DOI: 10.3414/ME0474 
Maifredi, G. Orizio, G. Bressanelli, M. Domenighini, S. Gasparotti, C. Perini, E. Gelatti, U. (2010). Italian Hospitals on The Web: A Cross-Sectional Analysis of Official Websites. BMC Medical Informatics and Decision Making, 10(1), 17. DOI: 10.1186/1472-6947-10-17

Mendi, B. Akyazı, E. (2016). Kurumsal İletişim Aracı Olarak Web Bilişim Sistemlerinin Kullanılabilirliğinde Teknoloji Kabulü (Hastane Web Sitelerine Yönelik Bir Araştırma). Gümüşhane Üniversitesi İletişim Fakültesi Elektronik Dergisi, 4(1), 447-477.

Metin, Y. (2012). Özel Hastanelerde Markalaşmanın Hasta Potansiyeline Etkisi. Ufuk Üniversitesi Sosyal Bilimler Enstitüsü, İşletme Anabilim Dalı, Yüksek Lisans Tezi, Ankara, 2012 (Tez Danışmanı: Prof. Dr. Mehmet Tomanbay).

Özsarı, S.H. Hoşgör, H. Gündüz, Hoşgör, D. (2016). Hastane Web Site Performanslarının Halkla İlişkiler ve Tanıtım Açısından İncelenmesi: Türkiye, Hindistan ve İrlanda Örnekleri. ACU Sağlık Bil Dergisi, 4, 209-217.

Patsioura, F. Kitsiou, S. Markos, A. (2009). Evaluation of Greek Public Hospital Websites. International Conference on E-business, July, 223-229.

Salarvand, S. Samadbeik, M. Tarrahi, M.J. Salarvand, H. (2016). Quality of Public Hospitals Websites: A Cross-Sectional Analytical Study in Iran. Acta Informatica Medica, 24(2), 130-133. DOI: 10.5455/aim.2016.24.130-133

Uğurluoğlu, Ö. (2009). İstanbul'daki Hastanelerin Web Sitesi Özellikleri Üzerine Bir İnceleme. Hacettepe Sağlık İdaresi Dergisi, 12(1), 87-104.

Yağar, F. Soysal, A. (2017). Markalaşma Sürecinde Etkili Olan Kurumsal Özellikler ve Tanıtım Faktörlerinin Hastane Tercihleri Üzerindeki Etkisi. Hacettepe Sağlık İdaresi Dergisi, 20(4), 457-474.

Yılmaz, E. (2013). Türkiye'de Hastaların İnternette Tıbbi Enformasyon Arama Davranışlarının DoktorHasta İletişimine Etkileri. Galatasaray Üniversitesi İletişim Dergisi, Özel Sayı 3, 93-108.

http://www.tuik.gov.tr/UstMenu.do?metod=temelist (11 Ekim 2018)

https://wearesocial.com (20 Mart 2018) 
EK 1: Türkiye Geneli ve 7 Coğrafi Bölgeye Göre Analiz Kriterlerinin Puan Ortalamaları

\begin{tabular}{|c|c|c|c|c|c|c|c|c|}
\hline Kriterler & Marmara & İç Anadolu & Ege & Akdeniz & $\begin{array}{l}\text { Güneydoğu } \\
\text { Anadolu }\end{array}$ & Karadeniz & Doğu Anadolu & $\begin{array}{c}\text { TÜRKIYE } \\
\text { ORTALAMASI }\end{array}$ \\
\hline 1-Genel Puan & 7,4 & 6,9 & 7,3 & 7,1 & 7,2 & 7,1 & 7,2 & 7,2 \\
\hline 2-Erişilebilirlik & 8,5 & 8,0 & 8,3 & 8,2 & 8,2 & 8,1 & 8,4 & 8,3 \\
\hline 3-Deneyim & 6,6 & 6,3 & 6,8 & 6,4 & 6,4 & 6,4 & 6,6 & 6,5 \\
\hline 4-Pazarlama & 4,9 & 4,6 & 4,9 & 4,7 & 5,1 & 5,0 & 4,5 & 4,8 \\
\hline 5-Teknoloji & 7,9 & 7,5 & 7,8 & 7,7 & 7,3 & 7,5 & 7,9 & 7,7 \\
\hline $\begin{array}{l}\text { 6-Erişim ve Cevap } \\
\text { Alma Hızı }\end{array}$ & 6,2 & 6,3 & 6,3 & 5,9 & 6,0 & 6,1 & 6,5 & 6,2 \\
\hline 7-Popülerlik & 3,1 & 3,3 & 3,1 & 3,2 & 3,1 & 3,4 & 2,4 & 3,1 \\
\hline 8-Sosyal İlgi & 4,5 & 4,4 & 4,5 & 4,4 & 5,1 & 4,7 & 4,7 & 4,6 \\
\hline \begin{tabular}{|l} 
9-Facebook Sayfası \\
Kullanımı
\end{tabular} & 2,1 & 1,8 & 3,3 & 2,4 & 3,3 & 2,3 & 2,5 & 2,5 \\
\hline 10-Twitter & 1,9 & 1,2 & 1,5 & 1,4 & 1,5 & 1,6 & 0,4 & 1,3 \\
\hline 11-Mobilite & 9,2 & 8,4 & 9,5 & 9,0 & 8,7 & 8,3 & 9,5 & 8,9 \\
\hline $\begin{array}{l}\text { 12-Fotoğraf ve } \\
\text { Görüntüler }\end{array}$ & 9,4 & 9,6 & 9,4 & 9,6 & 9,4 & 9,5 & 9,6 & 9,5 \\
\hline 13-Ana Başlıklar & 6,7 & 5,4 & 5,1 & 5,3 & 5,4 & 4,7 & 6,0 & 5,5 \\
\hline 14-Sayfa Başlıkları & 9,9 & 9,7 & 9,9 & 9,9 & 10,0 & 9,8 & 9,9 & 9,9 \\
\hline 15-İç Bağlantılar & 7,9 & 7,7 & 7,7 & 8,2 & 8,3 & 8,4 & 7,8 & 8,0 \\
\hline 16-Gelen Bağlantılar & 8,0 & 6,8 & 7,5 & 7,7 & 8,1 & 8,2 & 6,4 & 7,5 \\
\hline $\begin{array}{l}\text { 17-Bilgi İçeriği } \\
\text { Miktarı }\end{array}$ & 6,8 & 6,6 & 6,7 & 6,3 & 6,6 & 6,8 & 6,7 & 6,6 \\
\hline 18-Meta Etiketleri & 7,4 & 6,6 & 7,9 & 7,4 & 6,5 & 6,5 & 7,0 & 7,0 \\
\hline 19-URL Biçimi & 6,5 & 6,3 & 6,8 & 6,5 & 6,4 & 7,0 & 6,1 & 6,5 \\
\hline 20-Yazdırılabilirlik & 8,6 & 7,3 & 8,6 & 7,8 & 7,3 & 5,7 & 8,4 & 7,7 \\
\hline 21-Analiz & 8,7 & 7,1 & 8,5 & 7,0 & 7,8 & 7,2 & 7,6 & 7,7 \\
\hline 22-Güncellik & 6,4 & 7,0 & 7,2 & 6,3 & 6,3 & 7,4 & 7,3 & 6,8 \\
\hline
\end{tabular}

